\title{
Medical Devices and Combination Products: General Regulatory Framework
}

\author{
Ray Bakhtiar \\ Teva Branded Pharmaceutical Products $R \& D, U S A$
}

Received: February 4, 2017; Accepted: March 22, 2017; Published: April 5, 2017

*Corresponding author: Ray Bakhtiar, Teva Branded Pharmaceutical Products R \& D, Inc, West Chester, Pennsylvania, 19380, USA; E-mail: rbakhtiar@ msn.com

\begin{abstract}
During the last two decades, an unprecedented growth in innovative technologies has led to the development of state-ofthe-art medical devices in the healthcare sector. The regulatory aspects of medical devices are complex with variety of categories, ranging from a thermometer to diagnostic apparatuses, stents and catheters, syringes and hypodermic needles, blood transfusion and intravenous equipment, to robotically-assisted surgical devices (RASDs). In addition, there are subsets of medical devices such as in vitro diagnostics (IVD) or companion diagnostics (CDx) that provides information for the safe and effective use of a specific therapeutic agent. A natural extension of medical devices also includes combination products which could include two or more products from different categories such as medical device and/or a drug and/ or a biologic or possibly all three. In this manuscript, the current general regulatory framework for medical devices and combination products involving a medical device will be discussed.

Keywords: Medical Device; Combination Product; Premarket Approval; 510(k); In Vitro Diagnostics; Companion Diagnostics; Clinical Laboratory Improvement Amendments; Investigational Device Exemption
\end{abstract}

\section{Introduction}

The medical device industry is one of the fastest growing areas of pharmaceutical sector with a projected annual global market growth of about $4.4 \%$ [1]. In this regard, the medical device market is expected to out-perform the prescription drug market by 2018, which is expanding at a rate of about $2.5 \%$. The current global market for the medical devices is estimated to be at approximately $\$ 228$ billion [1]. Some of the major medical device companies include Johnson \& Johnson, General Electric Co., Medtronic, Abbott Laboratories, Siemens AG, Baxter International Inc., Fresenius Medical Care, Stryker Corp, Koninklijke Philips NV, and Cardinal Health Inc.

There are about 7000 medical device companies in the United States yielding an annual sale of $\$ 106-\$ 116$ billion, making it the largest in the world [1]. It is anticipated that due to aging global population and growth of emerging markets, countries such as China will continue to experience $20 \%$ or higher average annual growth rate for domestic medical devices with Europe accounting for at least $25-30 \%$ of the global market. Amongst a myriad of medical devices categories, diagnostic imaging devices occupy about $40 \%$ of the market share [1].

This article explores the regulatory framework by the United States Food and Drug Administration (USFDA) for medical devices as well as combination products such as device-drug and device-biologics. When appropriate, regulatory overlap and contrasts with other major regulatory agencies will also be presented. The general regulatory structures of other worldwide regulatory agencies, including China, are somewhat similar to the USFDA and European Union (EU) framework. In the emerging markets, the medical device development and regulation is still relatively new and work-in-progress. Hence, much of the countries outside of the US and EU communities relies upon import; however, this is expected to change over in future as part of the continued growth in their healthcare system and regulatory oversight [2].

\section{What is a medical device?}

The regulation of medical devices is through the Center for Devices and Radiological Health (CDRH) within the office of USFDA. Official regulation of medical devices started in 1976 (Table 1) with the Medical Device Amendments of 1976 to the Federal Food, Drug, and Cosmetic Act (FDCA) passed by the 94th United States Congress and signed on 28-May-1976 by President Gerald R. Ford (also known as Public Law 94-295). Section 201(h) of the FDCA defines a device as an instrument, apparatus, implement, machine, contrivance, implant or in vitro reagent, or other similar or related article, including any component, part, or accessory, which is:

-Recognized in the official National Formulary, or the United States Pharmacopoeia, or any supplement to them,

-Intended for use in the diagnosis of disease or other conditions, or in the cure, mitigation, treatment, or prevention of disease, in man or other animals, or

-Intended to affect the structure or any function of the body of man or other animals, and which does not achieve its primary intended purposes through chemical action within or on the body of man or other animals and which is not dependent upon being metabolized for the achievement of its primary intended 
purposes

Table 1: A historical overview of the medical device and combination products regulation by the USFDA

\begin{tabular}{|c|c|c|}
\hline Legislation & $\begin{array}{l}\text { Effective } \\
\text { Date }\end{array}$ & Comment \\
\hline $\begin{array}{l}\text { Federal Food \& } \\
\text { Drug Act }\end{array}$ & 1906 & $\begin{array}{c}\text { Did not include medical } \\
\text { devices }\end{array}$ \\
\hline $\begin{array}{l}\text { Food, Drug, and } \\
\text { Cosmetic Act }\end{array}$ & 1938 & $\begin{array}{l}\text { Extended control to cosmetics } \\
\text { and medical devices }\end{array}$ \\
\hline $\begin{array}{c}\text { New Drug } \\
\text { Amendments }\end{array}$ & 1962 & $\begin{array}{l}\text { The Kefauver-Harris } \\
\text { Amendments requiring } \\
\text { efficacy prior to marketing, } \\
\text { post-marketing surveillance, } \\
\text { and adverse event reporting }\end{array}$ \\
\hline $\begin{array}{l}\text { Medical Device } \\
\text { Amendments }\end{array}$ & 1976 & $\begin{array}{l}\text { Devices divided into } 3 \\
\text { categories with defined } \\
\text { approvals processes }\end{array}$ \\
\hline $\begin{array}{l}\text { Safe Medical } \\
\text { Devices Act }\end{array}$ & 1990 & $\begin{array}{l}\text { Additional reporting and } \\
\text { tracking rules with emphasis } \\
\text { on Class III devices }\end{array}$ \\
\hline $\begin{array}{l}\text { Medical Device } \\
\text { Amendments }\end{array}$ & 1992 & $\begin{array}{l}\text { Additional requirements } \\
\text { on device tracking, } \\
\text { user reporting, repair, } \\
\text { replacement, and post- } \\
\text { marketing surveillance }\end{array}$ \\
\hline $\begin{array}{c}\text { The Food \& Drug } \\
\text { Administration } \\
\text { Modernization } \\
\text { Act }\end{array}$ & 1997 & $\begin{array}{c}\text { Allowed accelerated reviews, } \\
\text { regulation of advertisements, } \\
\text { and reauthorized for } \\
\text { an additional } 5 \text { years, } \\
\text { with certain technical } \\
\text { improvements }\end{array}$ \\
\hline $\begin{array}{l}\text { Medical Device } \\
\text { User Fee \& } \\
\text { Modernization } \\
\text { Act }\end{array}$ & 2002 & $\begin{array}{l}\text { Multiple reforms to } \\
\text { medical device regulations, } \\
\text { authorization of user fees, } \\
\text { and establishment of the } \\
\text { Office of Combination } \\
\text { Products (OCP) }\end{array}$ \\
\hline $\begin{array}{l}\text { The Food \& Drug } \\
\text { Administration } \\
\text { Amendment Act }\end{array}$ & 2007 & $\begin{array}{l}\text { Reauthorization of medical } \\
\text { device user fees, new } \\
\text { pediatrics device provisions, } \\
\text { and clinical trial registry } \\
\text { for } 510(\mathrm{k}) \text { and PMA eligible } \\
\text { products }\end{array}$ \\
\hline $\begin{array}{l}\text { The Food \& Drug } \\
\text { Administration } \\
\text { Safety \& } \\
\text { Innovative Act }\end{array}$ & 2012 & $\begin{array}{l}\text { Reauthorization of the } \\
\text { Medical Device User Fee Act } \\
\text { (MDUFA III) for another } 5 \\
\text { years and implementation of } \\
\text { about three dozen medical } \\
\text { device provisions }\end{array}$ \\
\hline
\end{tabular}

In 1978, Current Good Manufacturing Practices (cGMP) promulgated including medical devices. The purpose of cGMPs was to ensure manufacturers establish and follow quality assurance programs to control production, packaging, storage, distribution, and installation of medical devices through a Quality System. In subsequent years, USFDA adopted the Quality System Regulation (QSR) which was mandated by the Safe Medical Devices Act (SMDA) in conjunction with harmonization of specific international requirements by the International Organization of Standards (ISO). The QSR is contained in Title 21 Part 820 CFR (Code of Federal Regulations).

Similarly, the EU has strict requirements prior to approval of a medical device for marketing per Directive 2007/47/ EC. Directives are legal obligations by manufacturers which lead the way for conformity assessment. There are several EU Medical Device Directives (MDD) for implementation of devices including 93/42EEC (MDD), 90/385/EEC (active implantable), and 98/79/ EC (in vitro diagnostics). Article 1 of the MDD defines a medical device as any instrument, apparatus, appliance, software, material or other article, whether used alone or in combination, including the software intended by its manufacturer to be used specifically for diagnostic and/or therapeutic purposes and necessary for its proper application, intended by the manufacturer to be used for human beings for the purpose of:

-Diagnosis, prevention, monitoring, treatment or alleviation of disease,

-Diagnosis, monitoring, treatment, alleviation of or compensation for an injury or handicap,

-Investigation, replacement or modification of the anatomy or of a physiological process,

-Control of conception,

And which does not achieve its principal intended action in or on the human body by pharmacological, immunological or metabolic means, but which may be assisted in its function by such means. Recent updates of Article 1 of the MDD has expanded the definition of a "medical device" to further elaborate on software, device subcategory, generic device groups, single-use devices, custom-made devices, and clarification of clinical data generated from the use of a medical device.

In 2011, analogous to the International Conference of Harmonization ( $\mathrm{ICH})$, representatives from the medical device regulatory authorities of Australia, Brazil, Canada, China, EU, Japan, the United States, and the World Health Organization (WHO) formed the International Medical Device Regulators Forum (IMDRF). The main objective of IMDRF is to harmonize medical devices regulation and discuss its future directions.

\section{Risk-based classification of medical devices}

Majority of regulatory authorities classify medical devices based on their risk to patients. Table 2 summarizes the USFDA classification per 1976 Medical Device Amendments, spanning from class I to III with increasing severity of risk. For example a class I, II, or III device could be a tongue depressor, an 
Table 2: Medical device and combination productsclassifications by the USFDA

\begin{tabular}{|c|l|}
\hline Classification & Comments \\
\hline Class I & $\begin{array}{c}\text { Low risk of harm to user; registration } \\
\text { only unless 510(k) clearance required; } \\
\text { compliance with general controls }\end{array}$ \\
\hline Class II & $\begin{array}{c}\text { Moderate risk of harm to user; } 510(\mathrm{k}) \\
\text { clearance unless waived; compliance with } \\
\text { general controls and special controls }\end{array}$ \\
\hline Class III & $\begin{array}{c}\text { High risk of harm to user; often requires } \\
\text { premarket approval (PMA); compliance } \\
\text { with general controls and PMA }\end{array}$ \\
\hline Combination & $\begin{array}{c}\text { Depending on the primary mode-of- } \\
\text { action (PMOA), may be reviewed by } \\
\text { multiple interagency divisions (see text } \\
\text { for more details) }\end{array}$ \\
\hline
\end{tabular}

infusion pump, and a heart valve, respectively. The China Food and Drug Administration (CFDA) medical class classification, Order No. 15, is broadly similar to the USFDA, divided into three distinct classes, I, II, and III.

In India, the medical devices are regulated by the Drug Controller General of India (DCGI) within the Central Drugs Standard Control Organization (CDSCO) under the Drugs and Cosmetics Act of 1940 and Drugs and Cosmetics Rules of 1945. Currently, only a select group of medical devices, referred to as the List of Notified Medical Devices, requires regulatory registration in India. Hence, there are no distinct device classifications by Indian authorities. Examples of devices requiring registration by an India Authorized Agent to interact with CDSCO, include bone cements, heart valves, blood component bags, condoms, cardiac stents, disposable hypodermic needles, and orthopedic implants.

The medical classifications by the EU, Canadian Drugs and Health products (DHP), Japanese Pharmaceuticals and Medical Devices Agency (PMDA), Russian Roszdravnadzor (RZN), Brazilian Agência Nacional de VigilânciaSanitária (ANVISA), and Australian Therapeutic Goods Act (TGA) are subdivided into four distinct categories as Class I through IV for DHP, ANVISA, and PMDA; and, Class I, IIa, IIb, and III for EU, RZN, and TGA $[3,4]$. The four levels of classification is based on low, low-moderate, moderate-high, and high risk to patients. Consequently, the Global Harmonization Task Force (GHTF), an organization similar to the International Conference of Harmonization (ICH), aimed at convergence at the global level, has also proposed four risk-based levels of classification as A, B, C, and D with increasing degree of risk. Lastly, beyond Classes I-IV, TGA has an additional subclass referred to as active implantable medical device category (AIMD) [3].

Generally, the device classification is assigned by the regulatory body. For example, CDRH with the USFDA is required by the 1976 Amendments to form advisory committees or classification panels to assist in device classifications. Hence, in accordance with 21 CFR 860, the classification panel makes recommendations to the Commissioner on the device class or reclassification. Considerations for classification include the duration of contact with the body, degree of invasiveness, and local versus systemic effect [5].

\section{Combination products}

Generally, a combination product is defined as two or more regulated products such as drug-medical device, biologicmedical device, drug-biologic, vaccine-medical device, or drugmedical-device-biologic (Table 3).

Table 3: Examples of medical devices or combination products by the USFDA

\begin{tabular}{|c|c|c|}
\hline Product & Indication & $\begin{array}{l}\text { Regulatory } \\
\text { classification }\end{array}$ \\
\hline $\begin{array}{l}\text { Automated external } \\
\text { defibrillator system } \\
\text { (non-wearable) }\end{array}$ & $\begin{array}{c}\text { Uses external pads to } \\
\text { be applied on suspected } \\
\text { victims of sudden cardiac } \\
\text { arrest }\end{array}$ & III \\
\hline \multirow{2}{*}{$\begin{array}{l}\text { AC-powered medical } \\
\text { examination light }\end{array}$} & & \\
\hline & $\begin{array}{l}\text { Accessories for lens to } \\
\text { improve magnified viewing }\end{array}$ & I \\
\hline \multirow{2}{*}{$\begin{array}{l}\text { Operating room table } \\
\text { (kit) }\end{array}$} & & \\
\hline & $\begin{array}{l}\text { Manual operating table and } \\
\text { accessories and chair }\end{array}$ & I \\
\hline $\begin{array}{l}\text { Diagnostic ultrasonic } \\
\text { imaging or monitoring } \\
\text { transducer }\end{array}$ & $\begin{array}{l}\text { Robotic component } \\
\text { maintains signal and } \\
\text { recovers lost signal }\end{array}$ & II \\
\hline \multirow[t]{2}{*}{ Artificial heart } & & \\
\hline & $\begin{array}{c}\text { Prosthetic device to replace } \\
\text { original biological heart }\end{array}$ & III \\
\hline \multirow{3}{*}{$\begin{array}{l}\text { Temporary cardiac } \\
\text { support blood pump }\end{array}$} & & \\
\hline & $\begin{array}{c}\text { Temporary circulating } \\
\text { support }<6 \text { hours of use } \\
\text { during a surgical procedure } \\
\text { with or without the use of } \\
\text { an oxygenator }\end{array}$ & III \\
\hline & & \multirow[t]{2}{*}{ II } \\
\hline $\begin{array}{l}\text { Folic acid } \\
\text { radioimmunoassay } \\
\text { test system }\end{array}$ & $\begin{array}{c}\text { Folic acid measurement } \\
\text { in plasma or serum for } \\
\text { diagnosis of megaloblastic } \\
\text { anemia }\end{array}$ & \\
\hline $\begin{array}{l}\text { Adhesive backed } \\
\text { thermal skin patch }\end{array}$ & $\begin{array}{c}\text { Temporary relief of pain for } \\
\text { muscle and joints associated } \\
\text { with arthritis and muscle } \\
\text { strains }\end{array}$ & I \\
\hline Angioscope & $\begin{array}{c}\text { To provide access, } \\
\text { illumination, and } \\
\text { observation or } \\
\text { manipulation of body } \\
\text { cavities, hollow organs, and } \\
\text { canals }\end{array}$ & II \\
\hline
\end{tabular}

Therefore, due to the multiple modalities involved, more than one regulatory agency office often reviews the sponsor's submission. For example, in order to streamline this process, the USFDA established the Office of Combination 
Products (OCP) in 2002, which inter-agency office will have the primary responsibility as a reviewer of the final product. The primary office assigned to the product review can then consult with the other two offices as part of the inter-center agreement between them. The jurisdictional offices for product reviews are the Center for Drug Evaluation and Research (CDER), the Center for Biologics Evaluation (CBER), and the Center for Devices and Radiological Health (CDRH).

Furthermore, there is an additional tool known as the Request-for-Designation (RFD) which is prepared by the sponsor and submitted to OCP. The RFD is used to request regulatory classification based on a proposed primary-mode-of-action (PMOA) and manufacturer's designation. The Agency then has 60 days to agree or disagree with the sponsor's classification. For example, the PMOA of a drug eluting stent is opening of the artery with CDRH assigned as the lead center. However, the PMOA of a drug eluting disk could be cancer chemotherapy with the lead center designated as CDER. Some medical devices require clinical human factor (HF) studies to ensure their ease of use by the targeted population.

\section{Registration process}

The medical device and combination productregistration processes vary amongst the regulatory agencies. For example, as mentioned earlier, the USFDA divides the medical devices into three distinct classes: I, III, and III (Tables 2\&3). Depending on the device, several regulatory pathways are available to the applicants including $510(\mathrm{k})$ premarket notification, reclassification, product development protocol (PDP), de novo review, and premarket approval (PMA) application.

A $510(\mathrm{k})$ filing, the device is "cleared" if it is substantially equivalent (SE) to an already marketed device referred to as a "predicate device". The reclassification process could include a petition to the USFDA to classify the device at a lower than originally requested (e.g., class III to II), in order to receive permission for marketing; while PDP's aim is to design preclinical and clinical studies by working closely with the USFDA in advance of any testing. The PDP option is rarely used at this point. The de novo review or so-called automatic reclassification is for those class I and II devices that have no predicate device after receiving a not substantially equivalent (NSE) response. Subsequent to receiving a NSE notice, the sponsor can file a petition for a de novo consideration. Finally, the more complex process is PMA for higher-risk life sustaining devices, often class III that requires a major commitment by the sponsor to conduct preclinical and clinical studies. The clinical studies related to a PMA submission are intended to support safety and efficacy and start with filing of an investigational device exempt (IDE) application for a clinical study initiation. The in vitro diagnostics (IVDs) can also be filed through a PMA or a $510(\mathrm{k})$ application.

\section{Conclusions}

The market for medical devices and combination products is rapidly growing. The development timelines for a medical device is often shorter than a novel chemical or biologic entity. Hence, appropriate timeline coordination needs to be taken into consideration for development of a combination product. Medical devices are produced under good manufacturing practices (GMP) requirements captured in QSRs. In EU, conformance to mandatory regulations is indicated by a CE marking on the medical device which certifies that the product has met safety criteria. Currently, the newly emerging areas of concern and discussion for some of the medical devices are cyber security to safeguard against breaches as well as introduction of $3 D$ printing $[6,7]$.

\section{References}

1. Cunningham J, Dolan B, Kelly D, Young C. Medical device sectoral overview. The Whitaker Institute for Innovation \& Societal Change and National University of Ireland Galway Report. 2015.

2. Sun P. Medical device regulation in China and the US: a comparison and a look forward. Intersect. The Stanford Journal of Science, Technology \& Society. 2012;5:1-16.

3. Schuh JC. Medical device regulations and testing for toxicological pathologists. Toxicol Patho. 2008;36(1):63-69. doi: 10.1177/0192623307309926

4. French-Mowat E, Burnett J. How are medical devices regulated in the European Union? J R Soc Med. 2012;105:S22-S28.

5. Sweet BV, Schwemm AK, Parsons DM. Review of the processes for the FDA oversight of drugs, medical devices and combination products. J Manag Care Pharm. 2011;17(1):40-50.

6. Owens B. Stronger rules needed for medical device cybersecurity. Lancet.2016;387(10026):1364.doi: 10.1016/S0140-6736(16)301209

7. Tack P, Victor J, Gemmel P, Annemans L. 3D-printing techniques in a medical setting: a systemic literature review. BioMed Eng OnLine. 2016;15(1):115. Doi 10.1186/s12938-016-0236-4 